\title{
AN UNUSUAL NEW GENUS OF CHRYSIDIDAE FROM OMAN (HYMENOPTERA)
}

\author{
BY LYNN SIRI KIMSEY* \\ Department of Entomology, \\ University of California, \\ Davis, CA 95616
}

The chrysidid tribe Elampini comprises a diverse group of genera. There are a number of small (1-3 species) highly derived genera in this group. Nearly all of these occur in 2 regions, southwestern North America and the area comprising the Middle East, southern USSR and North Africa. The small North American genera are Hedychreides Bohart, Microchridium Bohart, Minymischa Kimsey, Pseudolopyga Bodenstein and Xerochrum Bohart. Those in the latter region include: Haba Semenov, Prochridium Linsenmaier and the new genus, Adelopyga, described below. One genus, Muesebeckidium Krombein, occurs in both North and South America.

The following abbreviations are used: $F=$ flagellomere, $M O D=$ midocellus diameter, $\mathrm{PD}=$ puncture diameter, $\mathrm{Rs}=$ forewing radial sector, and $\mathrm{S}=$ gastral sternum.

\section{Adelopyga Kimsey, new genus.}

Type species: Adelopyga huberi Kimsey, new species.

Etymology: Adelo - "obscure", pyga - "tail”, taken from Holopyga, f., Grk.

Diagnosis. Scapal basin smooth with large punctures laterally and slightly rugose medially; F-I shorter than II, and pedicel; mandible with 1 subapical tooth; mesopleuron rounded, with distinct scrobe and oblique scrobal sulcus; female foretarsal claws edentate, mid and hindtarsal claws with single subparallel tooth; apical female fore and midtarsomeres curled, appearing prehensile; hindcoxa without dorsobasal carina; forewing Rs tiny, less than one-sixth stigmal length, stigma apically rounded and medial vein straight;

*Current address: Museum of Comparative Zoology-Entomology, Harvard University, Cambridge, MA 02138

Manuscript received by the editor April 7, 1987 
propodeum irregularly sculptured and punctate, without carinae, lateral angles small and broadly triangular; abdominal terga narrow and shallowly convex, sterna flat or shallowly convex; body with pale markings on mandibles and legs.

Discussion. In the Palearctic Region Adelopyga appears to be most closely related to Haba and Prochridium. It can be distinguished from both by the edentate female foretarsomeres and dentate mid and hindtarsomeres, the curled fore and midtarsi, very short Rs vein, straight medial vein, apically rounded stigma and narrow terga. The nearctic genus Minymischa is also similar to Adelopyga, particularly in the wing venation and coiled female fore and midtarsomeres. However, Adelopyga differs from Minymischa in the tarsal claw dentition, narrow terga, absence of a lateral pronotal carina and the short F-I.

It should be noted that the type and paratype specimens were preserved in alcohol and then critical point dried. The convexity of the abdominal sternum may be due to this treatment. If the sternum is actually flat or somewhat concave the abdomen would be very thin in profile.

Adelopyga huberi Kimsey, new species.

Holotype female. Body length $2 \mathrm{~mm}$. Face convex with depressed scapal basin and with large shallow punctures laterally 0.1-0.4 PD apart; scapal basin polished, smooth and impunctate; malar space 1 MOD long; frons and vertex with large, irregular shallow punctures, 0.2-2.0 PD apart; F-I 0.9X as long as broad, $0.6 \times$ as long as pedicel, $0.9 \times$ as long as F-II; F-II and V as long as broad; mandible with 1 subapical tooth; pronotum shorter than head length in dorsal view, with shallow scattered punctures $0.2-2.0$ PD apart, somewhat wrinkled laterally; scutal punctation same as pronotum, with fine transverse scratches particularly between parapsides and notauli; scutellum smooth with punctures 1.0-1.5 PD apart; mesopleuron with faint indication of oblique mesopleural carina, and about 8 large shallow punctures above scrobal sulcus, finely and densely scratched below scrobe; metanotum with punctures clumped along anterior half, impunctate posteriorly; propodeum irregularly sculptured and punctate, appearing roughened, without carinae on posterior surface, lateral angles small and broadly triangular; gastral terga shiny, with tiny, shallow punctures, 


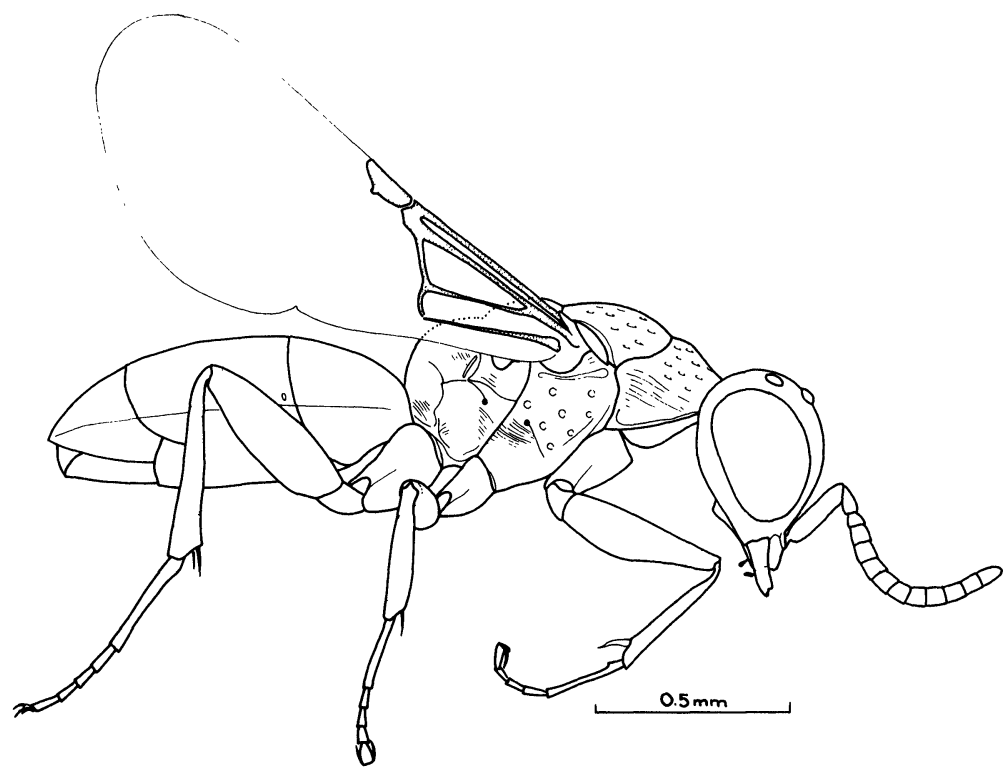

Fig. 1. Lateral view of female holotype of Adelopyga huberi.

1-4 PD apart or more. Head, thorax, tegula and terga shiny green; mandible basally green, medially off-white, apically red; femora green with nonmetallic yellow apex; foretibia and tarsi yellow; mid and hindtibia green medially, otherwise yellow; mid and hindtarsi yellow; wing veins pale yellow, membrane water clear; abdominal sterna brown, with small green medial spot on S-I and II.

Male unknown.

Holotype female-OMAN: Al Mintirib, n. end Wahiba sands, 26 February 1986, J. T. Huber. Paratype female, same data as type (DAVIS).

Discussion. The tiny size and coloration of this species make it quite distinctive and easily recognizable. This species is named in honor of the collector and fellow hymenopterist, John Huber.

\section{SuMmary}

The new chrysidid genus Adelopyga is described from Oman based on the new species huberi. 

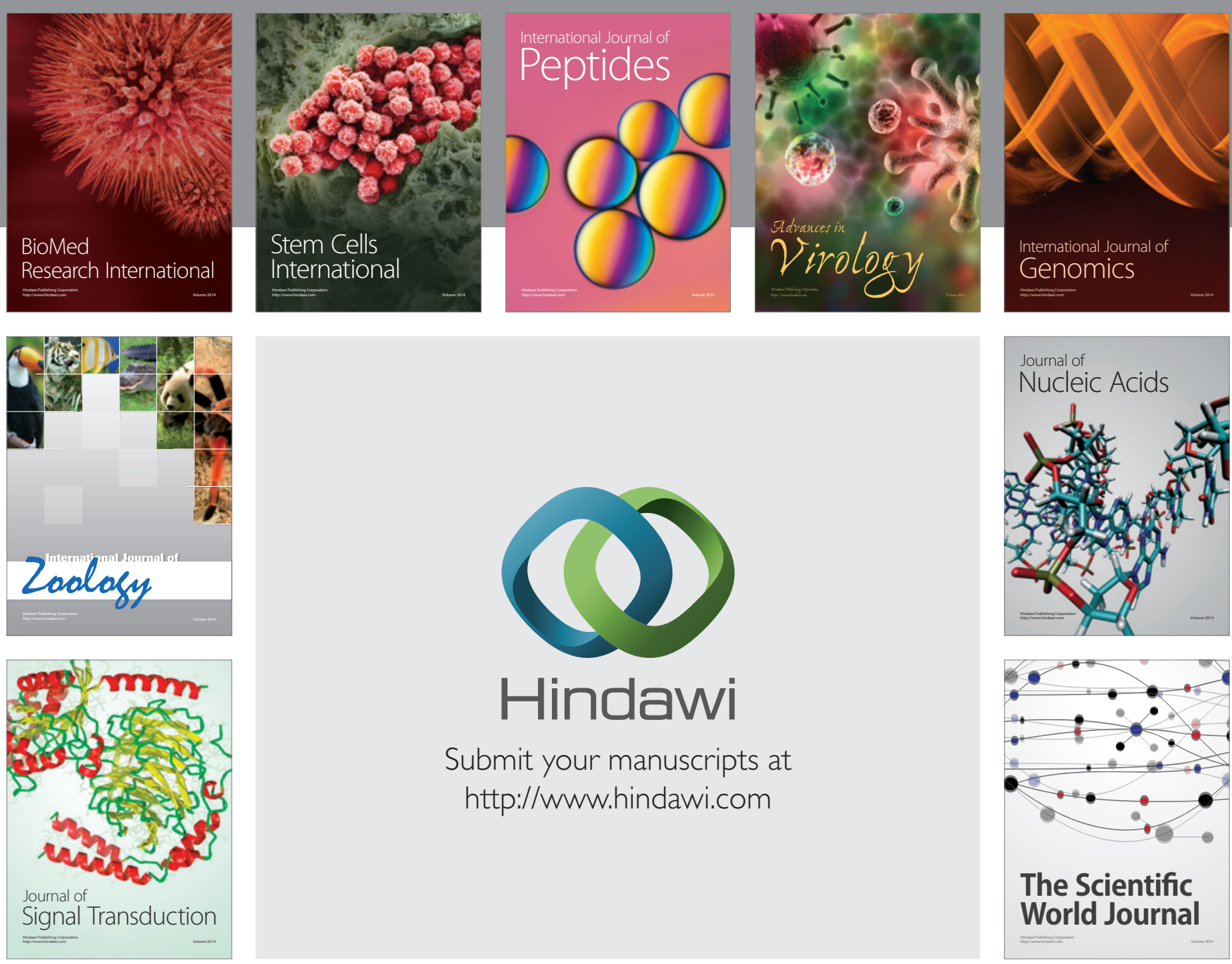

Submit your manuscripts at

http://www.hindawi.com
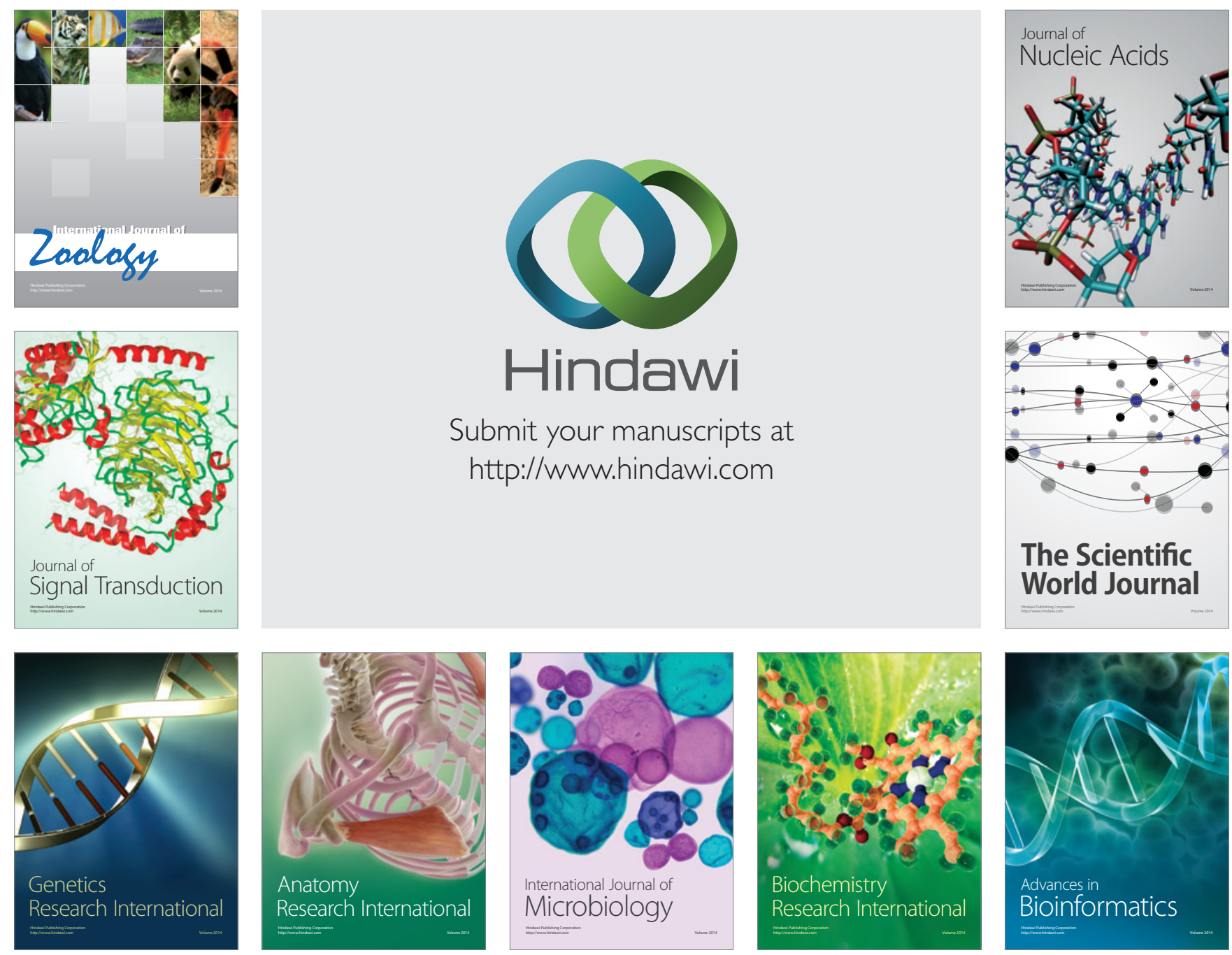

The Scientific World Journal
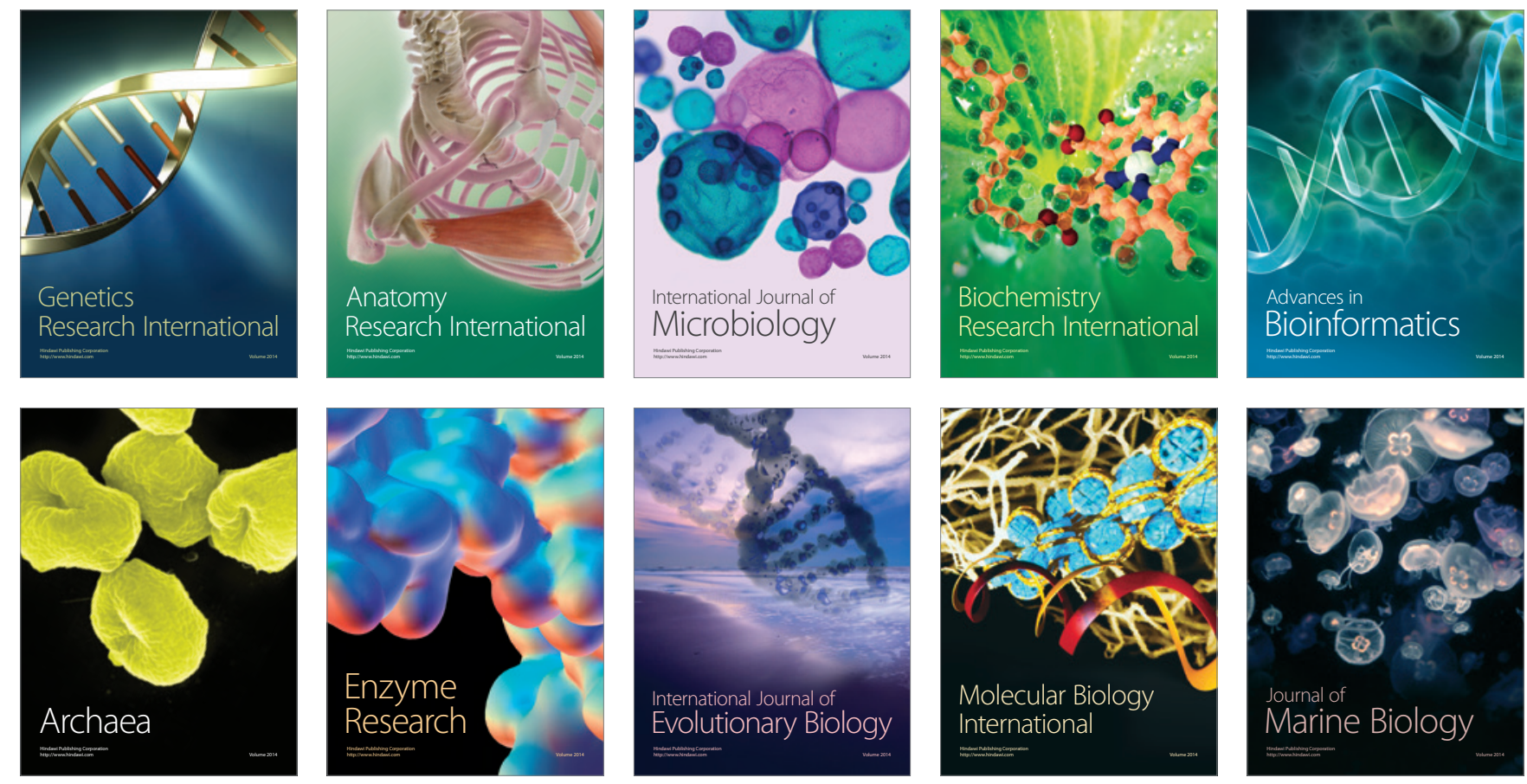